\title{
Study CAMBIMED: Effects of changes in medication appearance on safety of antihypertensive and hypolipidemic treatments in chronic patients older than 65 years in primary health care
}

\author{
Jesús Mario Arancon-Monge ${ }^{1 *}$, Alicia de-Castro-Cuenca², Ángel Serrano-Vázquez ${ }^{3}$, Luz Campos-Díaz ${ }^{4}$ \\ Montserrat Díaz-Eraso ${ }^{5}$, Isabel del Cura-González ${ }^{7,9}$, Elena Polentinos-Castro ${ }^{6,7}$, Ricardo Rodríguez-Barrientos ${ }^{7,8}$ \\ and Autores Colaboradores: GRUPO CAMBIMED
}

\begin{abstract}
Background: Different studies have investigated the effects that changes in drug appearance have on the control of chronic diseases and drug safety. The main objective of the proposed study is to evaluate if changes in the appearance of the packaging and presentation of drugs having the same active ingredient are related to a decrease in adherence and an increase in usage errors for chronic treatment using antihypertensive (enalapril and amlodipine) and hypolipidemic agents (simvastatin) in patients $\geq 65$ years old, over a one-year follow-up period.

Methods/Design: We propose a multicentric observational longitudinal cohort study with a one-year follow-up period in 8 primary health care centers (PHCC) in the Community of Madrid. 259 patients who are $\geq 65$ years old, hypertensive and/or dyslipidemic, undergoing treatment with enalapril and/or amlodipine and/or simvastatin, and under formal follow-up of chronic patients in primary health care will be selected by simple random sampling. The main outcome variable will be a final combined variable (adherence and medication usage errors). Other included variables will be: sociodemographic and clinical variables of the patient, degree of disease control, drug taken, number of changes in the appearance of each drug by the pharmacy, and the type and frequency of both avoidable and non-avoidable adverse effects during the follow-up period. A descriptive and a multivariate analysis of the variables will be carried out by means of a logistic regression model, using the final combined variable as the dependent variable (error and/or inadequate usage of the drug), and variables shown to be related to it during the bivariate analysis as the independent variables.

Discussion: For drugs of the same active ingredient, the effect that different package appearances and presentation may have on the safety of patients undergoing chronic treatments is unknown under the new legislative framework. There are various initiatives that promote the iso-appearance of drugs: "If they are the same, make them look the same". It is to be expected that older, multi-medicated patients with chronic pathologies will be the ones under a greater risk of suffering from this problem.
\end{abstract}

Keywords: Patient safety, Medication adherence, Medication errors, Look-alike, Appearance-equivalent

\footnotetext{
* Correspondence: mario.arancon@salud.madrid.org

${ }^{1}$ Gerencia de Atención Primaria, Servicio Madrileño de Salud, Cs Tres Cantos I, Sector Oficios 2, Tres Cantos 28760, Madrid, Spain
}

Full list of author information is available at the end of the article 


\section{Background}

In 2010 the Spanish National Health System (NHS) paid for 958 million prescriptions according to data from a report by the Spanish Society of Public Health and Health Administration. Due to this massive exposure of the population to drugs, and to a non-negligible percentage of patients who suffer avoidable adverse effects, the risks associated with drug usage acquire an enormous relevance from the public health perspective [1].

In 2011-2012, legislative changes have been introduced in order to lower the pharmaceutical expenses in the NHS that affect drug prescription. The Spanish law Real Decreto-ley 9/2011, from August 19 [2], requires the medical prescription to be made according to active ingredient, official Spanish denomination, or common international denomination. This way, homogeneous groupings are established for the same active ingredient in order to facilitate the interchangeability of drugs. Later, the Real Decreto-ley 16/2012, from April 20, which addresses urgent measures to ensure the sustainability of the NHS [3], requires dispensing the lowest priced drug out of all the pharmaceutical bio-equivalent presentations, among other measures.

Since the entry of these laws into effect, the doctor writes the prescription according to the active ingredient, with some exceptions (therapeutic needs and lower cost), and the final choice for the commercial brand is determined by the pharmacy based on the lowest-cost criteria. Therefore, the pharmacy can make the necessary changes in order to adjust to the economic criteria.

In this new legal framework, the patient can receive multiple presentations of the same drug when periodically renewing a chronic treatment using the same active ingredient, with different shapes, colors, and sizes of pills, excipients, and packages.

Without doubting the proven clinical efficacy of generic drugs or prescription by active ingredient, this situation generates worries in the medical field about the fact that these different presentations of the same active ingredient may increase the risk of drug usage errors in chronic treatments, since multiple changes of commercial brands can be made at the pharmacy [2], which may increase the risk of drug usage errors by patients. According to data from the APEAS study [4], which employed an observational design to study the safety of patients in primary care during standard clinical practice, examining over 96,000 consultations in the country during 2007, the prevalence of errors is estimated to be around $1.01 \%$, with an emphasis on the fact that in $48.2 \%$ of the cases the causes were related to medication.

Various authors and organizations have developed recommendations for alerting of this problem $[5,6]$. The US Institute for Safe Medication Practices (ISMP) recommends generic drugs keep the same appearance as the original brand, or a standard universal labeling be used for bio-equivalent medications. This Institute has a National Program of Medication Errors Notification in Spain (ISMP-España), where errors of mistaking different drugs with similar packages have been recorded, as happened with Renitec $5 \mathrm{mg}$ and $20 \mathrm{mg}$ and Zocor ${ }^{\circ}$ $10 \mathrm{mg}$ and $20 \mathrm{mg}$ because of having similar packaging. In Spain, various scientific societies (Spanish Society of Family and Community Medicine, Spanish Federation of Community Nursery, and Spanish Society of Attending Quality) have signed a manifesto under the motto "If they are the same, make them look the same", demanding actions so that packages of drugs containing the same active ingredient show a common appearance, which has been denominated "iso-appearance" [7].

Different studies have investigated the effects that changes in the appearance of drugs (package, shape, size, color) have on the control of chronic diseases. Of particular relevance is a systematic review by De Craen et al. [8], published in British Medical Journal, including 6 clinical trials that evaluated the effect of the color of pharmaceutical drug presentations on various factors, for example relating the drug color to a stimulating or depressive effect on the nervous system, or to the location of the effect. In addition to the placebo effect that different drug colors produce, color changes can confuse the patient, increasing the risk of errors. On the other hand, the change that happens at the pharmacies when dispensing medication with a different look may also affect the clinical control of the disease. The effects of drug appearance changes are centered on 2 mechanisms: medication errors (mistaking drugs, duplicating doses) and lack of adherence to treatment (either due to or independent of medication errors).

Undoubtedly, the most vulnerable population to these possible mistakes is the older, multi-medicated population. The changes in pharmaceutical presentations may mean an extra difficulty since they often suffer from visual deficiencies, and even cognitive ones, which can increase the risk of mistakes [9]. All this can generate confusion, forgetfulness, or duplication of dosages, which worsens adherence to the treatment, and therefore endangers their safety and even disease control [10]. The Spanish Ministry of Health, Social Services, and Equality itself establishes the investigation of the safety of medical treatments in the $>65$-year-old population as a strategic research line [11].

Lack of adherence to treatment is a problem of great relevance [12]. In the 2003 Geneva convention [13], the World Health Organization (WHO) already warned that only half of chronic treatments are followed correctly, and that adherence to them is an important modifier of the effectiveness of health systems. Among the causes for the lack of success of chronic treatments, the WHO 
refers to economical and social factors, the medical team assisting the patient, the health system, the characteristics of the disease, the treatment itself, and factors related to the patient. However, there are no studies that have evaluated the effect that repeated presentation changes may have on treatment adherence. Strategies have been proposed to avoid changes in commercial presentation, some of which imply manufacturing drugs with specific shapes (for example, the famous blue diamond of Viagra $\odot$ ), while others suggest directly advertising the specific look of the pill [14].

Hypertension (HTN) and dyslipidemia are two very prevalent chronic pathologies in our environment. The prevalence of HTN in Spain is estimated to be around $35 \%$, and almost doubles in patients over 65 years old (68\%); as for hypercholesterolemia, it is around 50\% when considering levels of total high cholesterol (HDL > $200 \mathrm{mg} / \mathrm{dL}$ or people under pharmacological treatment), or $44 \%$ if considering high levels of low density lipoproteins (LDL $>130 \mathrm{mg} / \mathrm{dL}$ or under pharmacological treatment) [15]. The 3 most prescribed drugs for these pathologies (enalapril, amlodipine, simvastatin) have been selected for this study, which have a high impact on the NHS due to the volume of prescriptions and the high number of patients who chronically consume them, according to data provided to the study auhors, by the NHS. The possibility of repeated changes at pharmacies for this group of drugs can be high; in the Spanish pharmaceutical market, there are currently 45 different presentations of enalapril $20 \mathrm{mg}, 40$ presentations of amlodipine $10 \mathrm{mg}$, and 47 presentations of simvastatin $20 \mathrm{mg}$ [16].

In primary health care, we find ourselves in a suitable framework to be able to observe under conditions of standard clinical practice the real effect of these legislative changes on patients with chronic diseases. The formal follow-up of these patients in primary health care will allow us to study the possible effects that appearance changes may have on adherence, possible usage errors, and clinical control of the disease.

\section{Aim}

The main aim of this study is to evaluate if changes of drugs with different package and/or presentation appearance for the same active ingredient are related to a decrease in adherence and an increase in usage errors, in patients $\geq 65$ years old, undergoing chronic treatment with antihypertensives (enalapril and/or amlodipine) and hypolipidemic agents (simvastatin), over a one-year follow-up period.

The secondary objectives are: to describe the number of drug changes made at pharmacies, estimate the frequency of avoidable and non-avoidable adverse effects during the follow-up period, describe the tolerance of patients to the dispensed drugs, and study if the number of changes is related to a decrease in the degree of control of blood pressure (BP) and/or LDL cholesterol.

\section{Methods/design \\ Design}

Observational longitudinal cohort study with a one-year follow-up period.

\section{Scope}

The study includes patients from 8 primary health care centers (PHCC) from the Community of Madrid: 2 urban ones (PHCC Avenida de Aragón, PHCC Benita de Avila), 3 suburban ones (PHCC Alameda de Osuna, PHCC El Puerto, PHCC Jaime Vera), and 3 rural ones (PHCC Paracuellos de Jarama, PHCC Las Matas, PHCC Fronteras), which attend a total population of approximately 205,000 .

\section{Patients}

All patients who are over 65 years old, diagnosed with HTN and/or hypercholesterolemia, and included in a program for following-up chronic patients in PHCCs will be included. The patient must be under treatment with at least one of the following drugs: enalapril, amlodipine, and simvastatin, with a stable dose during the previous 3 months, and must give informed, written consent.

The criteria for exclusion are: having difficulty to properly understand written or spoken Spanish, foreseeing an address change and not being ascribed to the PHCC for the following year, and suffering from severe systemic disease or other limitations that prevent the patient from attending the PHCC for the follow-up visits.

\section{Sample size}

Sample size has been calculated to estimate a proportions difference in the degree of adherence to the treatment of $20 \%$ between the exposed group (drug changes at the pharmacy) and the non-exposed group. It is estimated that adherence to treatments in the population undergoing chronic treatment is $50 \%$, and the odds ratio (OR) of suffering an event of adherence decrease is double in the group exposed to drug changes $(\mathrm{OR}=2)$ versus the non-exposed one.

For an alpha error of 0.05 and a beta error of 0.20, 237 patients would be necessary. Taking into account the effect of the doctor on adherence of their patients to treatment, it is considered that the outcome of each patient is not independent from other patients from the same cluster, so it is necessary to adjust the sample size because of the design effect. Considering that the number of included patients per doctor is 15 , and assuming an intraclass correlation coefficient of 0.01 [17], the 
required sample size would be 240 . If we estimate a $7 \%$ loss of patients to follow-up within a one-year period, the final sample size will be 259 patients.

\section{Sampling}

Random sampling will be performed out of the list of patients who fit the selection criteria ( $\geq 65$ years old, HTN and/or dyslipidemia, and treated with any of the 3 studied drugs) from each of the 30 participating doctors. Randomization will be performed by an independent researcher using computer software to create the randomization sequence (Excel 2007).

\section{Variables}

The main outcome variable is a final combined variable, defined as "having made some drug usage error and/or an inadequate adherence to treatment regimen".

Error in drug usage is defined according to the classification proposed by Ruiz-Jarabo et al. [18]. The type of error will be recorded (wrong dose, wrong frequency), as well as if there was injury to the patient, in which case the type and severity will also be recorded.

Inadequate adherence will be considered if more than one forgotten dose is detected during the package counting and/or if any of the answers (Yes/No) to the 4 questions of the Morisky-Green test in its validated Spanish version [19] is wrong. In the case of discrepancies between the Morisky test and the counting, the outcome of the counting will prevail. Since one single forgotten dose is a very stringent level of accomplishment, if no adherence differences are observed, different degrees of adherence $(80 \%, 90 \%$ and $110 \%)$ will be considered.

\section{Secondary outcome variables Sociodemographic}

Age, sex, level of education (illiterate, without studies, primary studies, secondary studies, superior education), and PHCC.

Related to the prescription and active ingredient:

- Prescribed active ingredient: enalapril, amlodipine, or simvastatin.

- Change of drug presentation at the pharmacy (Yes/No).

- Number of changes per drug.

- Suffering an adverse reaction to the drug (Yes/No), interruption of medication (Yes/No), and the reason for such interruption.

- Number of avoidable and non-avoidable adverse effects during the follow-up period.

- Tolerance of the patients to the dispensed drugs according to their own direct statement.
Clinical and analytical:

- Years of development of HTN and/or dyslipidemia. Presence of pathologies that modify the HTN (nephropathologies, sleep apnea, obesity, and malnutrition). Presence of pathologies that modify the lipid profile (hyperthyroidism, hypothyroidism, obesity, and malnutrition). Comorbidity (cardiovascular pathology, neurological pathology).

- Treatments that modify BP and the lipid profile (diuretics, alpha and beta blockers), antiinflammatories, antidepressants and anxiolytics, thyroxin, hormone replacement therapy. Other concomitant treatments.

- Figures of systolic blood pressure (SBP) and diastolic blood pressure (DBP) in each visit. Difference of SBP and DBP between the first visit and the last recorded data. Percentage of patients with good control at the beginning and at the end of the study.

- Total HDL cholesterol, LDL cholesterol, and triglycerides, both initial and after one year.

- Initial and final weight. Initial height. Difference in body mass index (BMI) between the first and final visits.

\section{Data collection}

Recruitment of patients will be done by their doctor (a study researcher) during a primary care consultation, who will collect the data for the various variables by means of a personal interview and review of the computerized clinical record, after having obtained informed consent, and will record it in an electronic notebook for data collection (Figure 1).

The study entails 5 visits during the trial period, set at $0,3,6,9$, and 12 months. Table 1 describes the visits scheme and the variables and measurements to be recorded during each one.

If adverse effects are detected, the notification system for adverse reactions will be followed according to standard clinical practice.

In the case that one patient does not attend a visit, at least 3 attempts to contact them by phone will be performed during different days and hours. Patients lost to follow-up and abandonments will be recorded and the reasons noted.

\section{Data analysis}

Data will be reviewed prior to analysis to guarantee its quality. A descriptive analysis will be performed on the characteristics (age and sex) of patients who refuse to participate in the study and the reasons for it will be described.

A descriptive analysis of each of the variables will be carried out. The mean and typical deviation will be 


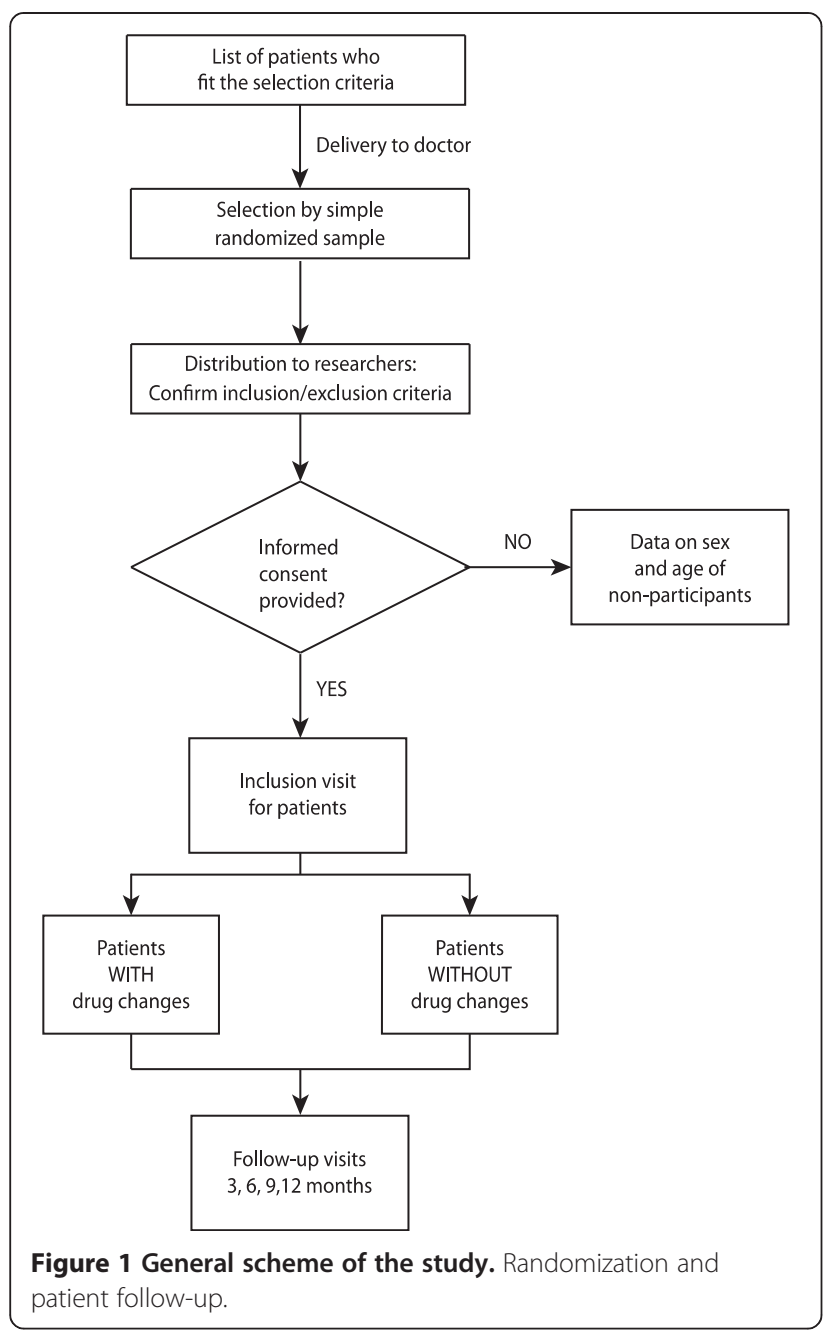

calculated in the case of symmetric distributions, and median and interquartile ranges will be estimated if the distribution is asymmetric. For categorical data, the frequency and percentage distributions will be shown. The difference of proportions will be estimated with its relevant confidence interval of $95 \%$.
The association of each of the independent variables with the dependent variable (adherence decrease and medication errors) will be studied, using Pearson's Chisquare test or Fisher's exact test (when the conditions to apply Chi-square are not satisfied) as the statistical tools to compare proportions, and the Student's T distribution or the Mann-Whitney U non-parametric test to compare the means.

A multivariate test with a logistic regression model will be performed, using the final combined variable (adherence and medication errors) as the dependent variable, and using as independent variables those identified to be associated in the bivariate analysis. All the hypothesis testing will be performed for all analysis', and a $\mathrm{p}<0.05$ will be accepted as significant. All the analysis methods will be adjusted considering cluster randomizations [20]. Statistical data analysis will be performed using SPSS 18.0 software.

\section{Ethical considerations}

This study has been approved by the Clinical Research Ethics Board of the Hospital de La Paz (February 5, 2012) in Madrid, and by the Central Research Board of Primary Health Care of the Community of Madrid.

The study will be carried out in accordance with Spanish law, complying with regulation on protection of personal data and patient's autonomy law. Patients will receive information about the study, both written and oral, and written consent will be obtained from all the participants prior to their inclusion in it.

\section{Discussion}

In our environment, the effects that new legislative measures related to drug prescription may have on the safety of the patient are unknown. For chronic treatment, the interchangeability of drugs with different package appearances and presentations for the same active ingredient may lead to mistakes when choosing the package, or to dose duplications, as well as affecting adherence to

Table 1 Visits and procedures to be performed

\begin{tabular}{|c|c|c|c|c|c|}
\hline & $\begin{array}{l}\text { Visit } 1 \text { Screening } \\
\text { (0 months) }\end{array}$ & $\begin{array}{l}\text { Visit } 2 \\
\text { (3 months) }\end{array}$ & $\begin{array}{l}\text { Visit } 3 \\
\text { (6 months) }\end{array}$ & $\begin{array}{l}\text { Visit } 4 \\
\text { (9 months) }\end{array}$ & $\begin{array}{l}\text { Visit } 5 \\
\text { (12 months) }\end{array}$ \\
\hline Recruitment following the selection criteria & $x$ & & & & \\
\hline Informed consent & $x$ & & & & \\
\hline $\begin{array}{l}\text { Initial collection clinical information and } \\
\text { sociodemographic data }\end{array}$ & $x$ & & & & \\
\hline BP control & $x$ & $x$ & $x$ & $x$ & $x$ \\
\hline Lipid profile control & $x$ & & & & $x$ \\
\hline Counting of drug packages & & $x$ & $x$ & $x$ & $x$ \\
\hline Morisky-Green test & $x$ & $x$ & $x$ & $x$ & $x$ \\
\hline Data collection for errors and adverse effects & & $x$ & $x$ & $x$ & $x$ \\
\hline Collection of followed-up clinical variables & & $x$ & $x$ & $x$ & $x$ \\
\hline
\end{tabular}


treatment by not taking or inadequately taking the medication. These errors may be much more frequent in more vulnerable populations, such as elderly or multimedicated patients.

Patients will be included and monitored in the study by their own primary care doctors according to standard practice. Including patients from different health professionals implies an increase of variability on the one hand, but on the other hand guarantees a lower number of losses to follow-up since they are chronic patients over 65 years old who periodically attend the PHCC, therefore enabling the analysis of the outcome under conditions of real clinical practice.

It must be highlighted that, in Spain, the majority of the population with the most prevalent chronic pathologies, such as HTN and dyslipidemia, is attended and supervised in primary health care.

In order to decrease the variability among health professionals, training sessions will be held and the protocol for the follow-up of hypertensive patients in primary health care in Madrid will be respected, having been implemented in the data collection notebook. Homologated, calibrated blood pressure meters will be used in order to guarantee the reliability of BP measurements.

We consider that despite the limitations that an observational study may have for answering our question, namely the lack of feasibility of performing a clinical trial as a result of not being able to randomize the intervention (interchangeability of drugs at the pharmacy), it will provide information on the possible effects that the recent legislative changes may have on patient safety.

The management of pharmaceutical services must be focused on both clinical and economic aspects, and must encompass all levels: prescription, dispensing, patients drug intake, and even the manufacturing by following the principle "if they are the same, make them look the same". The legislation changes based only on cost reduction and forgetful about improvement in medical prescription and pharmaceutical service may worsen the clinical situation and increase the consumption of resources in the long term. The most important is that the patient be the real aim for the outcome of all measures taken to improve their care.

\footnotetext{
Abbreviations

BMl: Body mass index; BP: Blood pressure; DBP: Diastolic blood pressure; HDL: High density lipoproteins; HTN: Arterial hypertension; LDL: Low density lipoproteins; NHS: National health system; OR: Odds ratio; PHCC: Primary health care center; SPSS: Statistical package for the social sciences; SBP: Systolic blood pressure; WHO: World Health Organization.
}

\section{Competing interests}

The authors declare that they have no competing interests.

\section{Authors' contributions}

JMAM conceived the idea, participated in the project design, and wrote this document. ACC is responsible for the graphic design, participated in the web design and correction, and coordination with the rest of the researchers. ICG, EPC, and RRB participated in the project design and the writing of this document, critically reviewing its intellectual content. The other members of CAMBIMED group: JMRR, JJOS, EMIC, MCMM, PSGLB, MDE, GTP, MFVG, MGV, CFM, AGA, VMB, JCAS, MIRR, LCD, MGC, AMHT, JPT, ASV, $C G B, C C l, M D M C, Y U S, D G G, N D P$, and MVF have reviewed the project and given their approval to the final version of its protocol.

\section{Acknowledgements}

To Beatriz de Castro Cuenca, usability consultant, for her altruistic input in the logo graphic design and presentations.

To Noel Aguilera López, computer engineer, for his willingness to execute the Data Collection Notebook and website.

To the SOMAMFYC, for providing the spaces to hold work meetings. To Teresa Sanz-Cuesta, Milagros Rico-Blázquez, and the Research Support Unit of the Primary Care Management of Madrid, for their support on methodology to design and start the project.

\section{Funding}

This project is financed by the Spanish Health Ministry through the convening of grants for the promotion of independent clinical research of 2011. File number EC11-220.

This project has been awarded with the Prize to the Best National Research Project 2012 during the XXXII Congress of the Spanish Society for Family and Community Health Care, Bilbao, June 13-15, 2012.

\section{Clinical assistance CAMBIMED GROUP}

Primary healthcare center (PHCC) Tres Cantos I (Madrid): Jesús Mario Arancón Monge

Primary healthcare centre (PHCC) Paracuellos de Jarama (Madrid) José María Rubio-Ruiz, Jesús Juan Ortiz-Septien, Eva María Illana-Calero, María Cristina Martín-Muñoz, Paula Silvana González-de-Langarica-Bouza. PHCC Jaime Vera (Coslada): Alicia de-Castro-Cuenca, María Isabel RoucoRegueira.

PHCC El Puerto (Coslada): Ángel Serrano-Vázquez, Cristina García- Benito, Carmen Colomes less, María Dolores Miranda Carrasco, Yolanda Úbeda Sánchez, David García Gutiérrez, Nuria Domínguez Pérez.

PHCC Avenida de Aragón (Madrid ): Luz Campos-Díaz, Mercedes García Culebras.

PHCC Las Fronteras (Torrejón): Montserrat Díaz Eraso, Generoso Tejedor Pérez, María Fernanda Venegas Gato, Mar García Viada, Carmen Fuentes Manrique, Asunción García Alonso, Verónica Molina Barcena. PHCC Benita de Ávila ( Madrid): Josefina Piñera Támes PHCC Monterrozas-Las Matas ( Las Rozas): Margarita Villar Fidalgo PHCC Alameda de Osuna ( Madrid): Ana Ma Herranz Torrubiano

\section{Autores Colaboradores: GRUPO CAMBIMED}

José María Rubio-Ruiz, JMRR.Centro de Salud Paracuellos de Jarama. Gerencia de Atención Primaria. Servicio Madrileño de Salud. (Calle Chorrillo alta, 26). Paracuellos de Jarama (28860), Madrid, Spain. jrubio.gapm05@salud. madrid.org

Jesús Juan Ortiz-Septien, JJOS. Centro de Salud Paracuellos de Jarama. Gerencia de Atención Primaria. Servicio Madrileño de Salud. (Calle Chorrillo alta, 26). Paracuellos de Jarama (28860), Madrid, Spain. jjortiz.gapm11@salud. madrid.org

Eva María Illana-Calero, EMIC. Centro de Salud Paracuellos de Jarama. Gerencia de Atención Primaria. Servicio Madrileño de Salud. (Calle Chorrillo alta, 26). Paracuellos de Jarama (28860), Madrid, Spain. evillana. gapm05@salud.madrid.org

María Cristina Martín-Muñoz, MCMM. Centro de Salud Paracuellos de Jarama. Gerencia de Atención Primaria. Servicio Madrileño de Salud. (Calle Chorrillo alta, 26). Paracuellos de Jarama (28860), Madrid, Spain. mcmartinm. gapm05@salud.madrir.org

Paula Silvana González-de-Langarica-Bouza, PSGLB. Centro de Salud Paracuellos de Jarama. Gerencia de Atención Primaria. Servicio Madrileño de Salud. (Calle Chorrillo alta, 26). Paracuellos de Jarama (28860), Madrid, Spain. pgonzalez.gapm09@salud.madrid.org

Generoso Tejedor-Pérez, GTP. Centro de Salud Fronteras. Gerencia de Atención Primaria. Servicio Madrileño de Salud. (Calle Puerto de Navacerrada, 4). Torrejón de Ardoz (28850), Madrid, Spain. Generoso. Tejedor@salud.madrid.org 
María Fernanda Venegas-Gato, MFVG. Centro de Salud Fronteras. Gerencia de Atención Primaria. Servicio Madrileño de Salud. (Calle Puerto de Navacerrada, 4). Torrejón de Ardoz (28850), Madrid, Spain. mfvenegas. gapm03@salud.madrid.org

Mar García-Viada, MGV. Centro de Salud Fronteras. Gerencia de Atención Primaria. Servicio Madrileño de Salud. (Calle Puerto de Navacerrada, 4). Torrejón de Ardoz (28850), Madrid, Spain. mgarciav.summa@salud.madrid.org Carmen Fuentes-Manrique, CFM. Centro de Salud Fronteras. Gerencia de Atención Primaria. Servicio Madrileño de Salud. (Calle Puerto de Navacerrada, 4). Torrejón de Ardoz (28850), Madrid, Spain. mfuentes. gapm03@salud.madrir.org

Asunción García-Alonso, AGA. Centro de Salud Fronteras. Gerencia de Atención Primaria. Servicio Madrileño de Salud. (Calle Puerto de Navacerrada, 4). Torrejón de Ardoz (28850), Madrid, Spain. magarcia.hrc@salud.madrid.org Verónica Molina-Bárcena, VMB.Centro de Salud Fronteras. Gerencia de Atención Primaria. Servicio Madrileño de Salud. (Calle Puerto de Navacerrada, 4). Torrejón de Ardoz (28850), Madrid, Spain. verónica. molina@salud.madrid.org

María Isabel Rouco-Regueira, MIRR. Centro de Salud Jaime Vera. Gerencia de Atención Primaria Servicio Madrileño de Salud. (Avenida de España S/N). Coslada (28822), Madrid, Spain. m.isabel.rouco@salud.madrid.org Mercedes García-Culebras, MGC. Centro de Salud Avenida de Aragón. Gerencia de Atención primaria. Servicio Madrileño de Salud. (Calle Alcalá, 425). Madrid (28027), Madrid, Spain. mercedes.garciacu@salud.madrid.org Ana María Herranz-Torrubiano, AMHT. Centro de Salud Alameda de Osuna. Gerencia de Atención Primaria. Servicio Madrileño de Salud (CalleCarabela, 7). Madrid (28042), Madrid, Spain. amherranz.gapm09@salud.madrid.org Josefina Piñera-Tames, JPT. Centro de Salud Benita de Ávila. Gerencia de Atención Primaria. Servicio Madrileño de Salud. (Calle Benita Ávila, 26). Madrid (28043), Madrid, Spain. mpinera.gapm04@salud.madrid.org Cristina García-Benito, CGB.Centro de Salud El Puerto. Gerencia de Atención Primaria. Servicio Madrileño de Salud. (Calle Océano Pacífico, 3). Coslada (28821), Madrid, Spain. cgarcia.gapm02@salud.madrid.org

Carmen Colomes-less, CCl. Centro de Salud El Puerto. Gerencia de Atención Primaria. Servicio Madrileño de Salud. (Calle Océano Pacífico, 3). Coslada (28821), Madrid, Spain. mcarmen.colomes@salud.madrir.org

María Dolores Miranda-Carrasco, MDMC. Centro de Salud El Puerto. Gerencia de Atención Primaria. Servicio Madrileño de Salud. (Calle Océano Pacífico, 3). Coslada (28821), Madrid, Spain. mdolores.miranda@salud. madrid.org

Yolanda Úbeda-Sánchez, YUS. Centro de Salud El Puerto. Gerencia de Atención Primaria. Servicio Madrileño de Salud. (Calle Océano Pacífico, 3). Coslada (28821), Madrid, Spain. Yolanda.ubeda@salud.madrid.org David García-Gutiérrez, DGG. Centro de Salud El Puerto. Gerencia de Atención Primaria. Servicio Madrileño de Salud. (Calle Océano Pacífico, 3). Coslada (28821), Madrid, Spain. dgarcia@salud.madrid.org Nuria Domínguez-Pérez, NDP. Centro de Salud El Puerto. Gerencia de Atención Primaria. Servicio Madrileño de Salud. (Calle Océano Pacífico, 3). Coslada (28821), Madrid, Spain. nuria.dominguezp@salud.madrid.org Margarita Villar-Fidalgo, MVF. Consultorio Las Matas. Gerencia de Atención Primaria. Servicio Madrileño de Salud. (Calle Paseo de los Alemanes, 31). Las Rozas de Madrid (28290), Madrid, Spain. mvillar.gapm06@salud. madrid.org

\section{Author details}

${ }^{1}$ Gerencia de Atención Primaria, Servicio Madrileño de Salud, Cs Tres Cantos I, Sector Oficios 2, Tres Cantos 28760, Madrid, Spain. ${ }^{2}$ Centro de Salud Jaime Vera. Servicio Madrileño de Salud, Gerencia de Atención Primaria, Avenida de España S/N, Coslada 28822, Madrid, Spain. ${ }^{3}$ Centro de Salud El Puerto, Gerencia de Atención Primaria, Servicio Madrileño de Salud, Calle Océano Pacífico 3, Coslada 28821, Madrid, Spain. ${ }^{4}$ Centro de Salud Avenida de Aragón, Gerencia de Atención primaria, Servicio Madrileño de Salud, Calle Alcalá, 425, Madrid 28027, Madrid, Spain. ${ }^{5}$ Centro de Salud Fronteras, Gerencia de Atención Primaria, Servicio Madrileño de Salud, Calle Puerto de Navacerrada 4, Torrejón de Ardoz 28850, Madrid, Spain. ${ }^{6}$ UDM Atención Familiar y Comunitaria Norte, Unidad de Apoyo a la Investigación, Gerencia de Atención Primaria, Servicio Madrileño de Salud, Calle San Martín de Porres 6, Madrid 28035, Madrid, Spain. ${ }^{7}$ Red de Investigacion en Servicios de Salud en enfermedades crónicas (REDISECC), Madrid, Spain. ${ }^{8}$ Unidad de Apoyo Técnico, Unidad de Apoyo a la Investigación, Gerencia de Atención Primaria, Servicio Madrileño de Salud, Calle San Martín de
Porres 6, Madrid 28035, Madrid, Spain. ${ }^{9}$ Unidad de Apoyo a la Investigación. Gerencia de Atención Primaria, Servicio Madrileño de Salud, Calle San Martín de Porres 6, Madrid 28035, Spain.

\section{Received: 29 December 2014 Accepted: 30 December 2014} Published online: 04 March 2015

\section{References}

1. Sanfélix-Gimeno G, Peiró S, Meneu R. Pharmaceutical prescription in primary care. SESPAS report 2012. Gac Sanit. 2012;26 Suppl 1:41-5.

2. Real Decreto-ley 9/2011, De 19 De Agosto. Medidas Para La Mejora De La Calidad y Cohesión Del Sistema Nacional De Salud, De Contribución a La Consolidación Fiscal, y De Elevación Del Importe Máximo De Los Avales Del Estado Para 2011. Boletín Oficial del Estado n²00; 2011.

3. Real Decreto-ley 16/2012, De 20 De Abril. Medidas Urgentes Para Garantizar La Sostenibilidad Del Sistema Nacional De Salud y Mejorar La Calidad y Seguridad De Sus Prestaciones. Boletín Oficial del Estado nº 98; 2012.

4. Ministerio de Sanidad. Estudio APEAS: Estudio Sobre La Seguridad De Los Pacientes En Atención Primaria De Salud. 2008.

5. Grupo de seguridad del paciente [http://sano-y-salvo.blogspot.com/feeds/ posts/default]

6. Greene JA, Kesselheim AS. Why do the same drugs look different? Pills, trade dress, and public health. N Engl J Med. 2011;365:83-9.

7. SEMFYC. La semFYC, la FAECAP y la SECA lanzan una campaña para conseguir la Isoapariencia. 2011. http://www.semfyc.es/es/noticias/ destacadas/detalle/Campana_Isoaparencia/.

8. De Craen AJ, Roos PJ, LeonarddeVries A, Kleijnen J. Effect of colour of drugs: systematic review of perceived effect of drugs and of their effectiveness. BMJ (Clinical research ed). 1996;313(7072):1624-6.

9. Alós Almiñana M, Bonet Deán M. Retrospective analysis of adverse sideeffects of medication in elderly patients at a primary care health centre. Aten Primaria. 2008;40:75-80.

10. Vik SA, Maxwell CJ, Hogan DB. Measurement, correlates, and health outcomes of medication adherence among seniors. Ann Pharmacother. 2004;38:303-12.

11. Orden SPI/2885/2011 de 20 de O. Convocatoria Para La Concesión De Ayudas Para El Fomento De La Investigación Clínica Independiente. Boletín Oficial del Estado, The Spanish Ministry of Health; 2011.

12. Cutler DM, Everett W. Thinking outside the pillbox-medication adherence as a priority for health care reform. N Engl J Med. 2010;362:1553-5.

13. Burkhart PV, Sabaté E. Adherence to long-term therapies: evidence for action. J Nurs Scholarsh. 2003;35:207.

14. Donohue JM, Cevasco M, Rosenthal MB. A decade of direct-to-consumer advertising of prescription drugs. N Engl J Med. 2007;357:673-81.

15. Perk J, De Backer G, Gohlke H, Graham I, Reiner Z, Verschuren M, et al. European Guidelines on cardiovascular disease prevention in clinical practice (version 2012). The Fifth Joint Task Force of the European Society of Cardiology and Other Societies on Cardiovascular Disease Prevention in Clinical Practice (constituted by representatives of nine societies and by invited experts). Eur Heart J. 2012;33:1635-701.

16. Ministerio de Sanidad. Data base Nomenclátor DIGITALIS. Ministry of Health of Spain.

17. Adams G, Gulliford MC, Ukoumunne OC, Eldridge S, Chinn S, Campbell MJ. Patterns of intra-cluster correlation from primary care research to inform study design and analysis. J Clin Epidemiol. 2004;57:785-94.

18. Otero López MJ, Codina Jané C, Tamés Alonso MJ, Pérez Encinas M. [Medication errors: standarizing the terminology and taxomany. Ruiz Jarabo 2000 grand results]. Farm Hosp. 2003;27:137-49.

19. Val Jiménez A, Amorós Ballestero G, Martínez Visa P, Fernández Ferré ML, León Sanromà M. Descriptive study of patient compliance in pharmacologic antihypertensive treatment and validation of the Morisky and Green test. Aten Primaria. 1992;10:767-70.

20. Mollison J, Simpson JA, Campbell MK, Grimshaw JM. Comparison of analytical methods for cluster randomised trials: an example from a primary care setting. J Epidemiol Biostat. 2000;5:339-48. 